\title{
De politiek van buy-to-let
}

\author{
Jelke Bosma, Cody Hochstenbach, Rodrigo Fernandez \& Manuel Aalbers ${ }^{*}$
}

\section{Inleiding}

De toegenomen populariteit van de stad in Nederland, maar ook in veel andere landen, leidt tot toenemende druk op zowel de betaalbaarheid als de toegankelijkheid van de woningmarkt. Niet alleen stijgen de prijzen op de koopmarkt razendsnel, betaalbare huurwoningen zijn ook steeds moeilijker te vinden. Zeker voor nieuwkomers en andere buitenstaanders op de woningmarkt is het lastiger geworden om aan een geschikte woning te komen. Deze ontwikkelingen kunnen worden gezien als onderdeel van een nieuwe stedelijke wooncrisis (Hochstenbach, 2017).

In het licht van deze ontwikkelingen bestaan er veel zorgen over de veronderstelde opmars van investeerders op de woningmarkt (zie onder andere Couzy \& Van Dun, 2017). Zij zouden grote aantallen koopwoningen opkopen en verhuren tegen hoge huren; in de internationale literatuur wordt dit geduid als buy-to-let. Er wordt regelmatig beschuldigend naar buy-to-let gewezen als oorzaak van prijsopdrijving, uitsluiting en uitwassen op de woningmarkt. Concreet onderzoek naar buy-to-let is echter nog schaars. In deze bijdrage schetsen wij daarom hoe buy-tolet zich de afgelopen jaren in Nederlandse steden heeft ontwikkeld en welke invloed dit heeft op de woningmarkt.

De Nederlandse situatie staat echter niet op zichzelf. In veel westerse landen wint buy-to-let aan terrein en draagt het bij aan een veranderende woningmarktstructuur. Een voorloper in dit opzicht is het Verenigd Koninkrijk: daar zorgt buy-tolet al langere tijd voor een groei van de particuliere huursector en een krimp van het aantal koopwoningen. Vervolgens zijn daar ook maatregelen geïntroduceerd om buy-to-let aan banden te leggen. Verschillende grensoverschrijdende macroeconomische ontwikkelingen - zoals lage rentestanden en de overvloedige beschikbaarheid van mobiel kapitaal - spelen een rol bij deze internationale opmars.

De neiging lijkt te bestaan buy-to-let als een opzichzelfstaand fenomeen te beschouwen, één waar nationaal en lokaal woonbeleid slechts beperkt grip op hebben. In dit artikel betogen wij dat buy-to-let gezien kan worden als de uitkomst van langlopende economische en politieke ontwikkelingen, van bredere hervormingen op zowel de koop- als de huurwoningmarkt. Lange tijd vormde het

* Jelke Bosma MSc is junior onderzoeker aan de Universiteit van Amsterdam. Dr. Cody Hochstenbach is postdoctoraal onderzoeker stadsgeografie aan de Universiteit van Amsterdam, en redactielid van Beleid en Maatschappij. Dr. Rodrigo Fernandez is postdoc aan de KU Leuven en onderzoeker bij SOMO. Prof. dr. Manuel Aalbers is hoogleraar sociale en economische geografie aan de KU Leuven. 
garanderen van voldoende betaalbare woningen een centraal onderdeel van de verzorgingsstaat (Van der Schaar, 1987). De staat heeft zijn rol de afgelopen decennia echter opnieuw ingevuld. De staat trok zich niet zozeer terug van het terrein van de woningmarkt, maar heeft zijn accenten wel stevig verlegd: eigenwoningbezit is aanzienlijk gegroeid; door hypotheekrenteaftrek en meer en grotere hypotheken zijn huizenprijzen de lucht in geschoten, huurwetgeving is versoepeld en woningcorporaties zijn in een marktomgeving gaan opereren.

Tegen deze achtergrond brengt dit artikel de invloed van investeerders op de stedelijke woningmarkt in kaart. De volgende paragraaf presenteert een internationaal perspectief op buy-to-let aan de hand van wetenschappelijke literatuur. Vervolgens brengen wij aan de hand van kwantitatieve data in kaart in hoeverre er daadwerkelijk sprake is van een opmars van buy-to-let. Ten slotte besteden wij aandacht aan de invloed van beleidskeuzes op het faciliteren van beleggers op de woningmarkt. Dit artikel put hierbij uit ons begin 2018 gepubliceerde onderzoeksrapport Buy-to-let gewikt en gewogen (Aalbers e.a., 2018).

\section{Internationaal theoretisch perspectief}

Het dominante narratief in Nederland is dat de nieuwe crisis op de woningmarkt is veroorzaakt door een combinatie van een lage rente, de hypotheekrenteaftrek, de komst van beleggers en een periode van lage woningbouwproductie na de grote financiële crisis. Vergelijkbare problemen van onbetaalbare koop- en huurwoningen en daarmee samenhangende gentrificatie, sociale uitsluiting en segregatie doen zich echter ook voor in andere steden in andere landen. Dit is bijzonder, omdat woningmarkten institutioneel complex zijn en gebonden zijn aan een specifieke nationale institutionele configuratie. Het suggereert dat naast nationale eigenschappen ook grensoverschrijdende mechanismen aan het werk zijn. Daarom is het verstandig om de Nederlandse woonproblematiek met een bredere blik te benaderen.

Sinds de jaren tachtig heeft zich een aantal ontwikkelingen voorgedaan in meerdere ontwikkelde economieën die een nieuwe structurele inbedding van woningmarkten hebben gecreëerd. Hierbij valt te denken aan een toename van het eigenwoningbezit, een stijging van de hypotheekschuld en een daarmee samenhangende toename in woonvermogen (Doling \& Elsinga, 2012; Fernandez \& Aalbers, 2016; Wind, 2017). Deze ontwikkelingen leiden tezamen tot een verschuiving van huur naar koop en tot een toegenomen rol van de woning als investeringsobject.

Het belang van vastgoed als aanjager van consumptie en investeringen is toegenomen. In veel ontwikkelde economieën heeft zich een parallel proces voltrokken, waarbij vastgoed onderdeel is geworden van een dominant schuldgedreven groeimodel (Hudson, 2012). Vastgoed als vliegwiel voor economische groei was niet overal dominant; met name in mediterrane en Oost Europese landen (met uitzondering van Spanje) en landen als Frankrijk, Duitsland en Oostenrijk speelde dit tot voor kort veel minder (Fernandez \& Aalbers, 2016). In dit proces zijn woningen uiteindelijk van een sociaal recht een investeringsobject geworden en 
zijn zo een cruciaal deel van de financialisering van het alledaagse (Aalbers, 2008; Langley, 2006).

Herman Schwartz en Leonard Seabrooke (2008) stellen dat de woningmarktstructuur een centraal onderdeel behoort te zijn van analyses van de politieke economie, en niet alleen om de relatie met de verzorgingsstaat te begrijpen. Ze introduceren daarom het idee van nationaal gebonden typen van 'residentieel kapitalisme' - afhankelijk van onder meer het eigenwoningbezit en de hypotheekschuld. Naast diverse nationale woningmarktmodellen identificeren Schwartz en Seabrooke een overlappend proces van financialisering dat samenhangt met globalisering en financiële innovatie. Dit overlappende proces betekent dat hypotheken niet meer exclusief het doel hebben om woningen te financieren, maar hiernaast, door de centrale rol van securitiseren, onderdeel zijn van een lange keten van financiële intermediairs, die grotendeels eindigt bij institutionele beleggers. Woningen zijn hierdoor een belangrijke grondstof geworden voor innovatie op financiële markten. Kortom, woningen zijn veranderd van plaatsgebonden illiquide investeringen in een onderpand voor een wereldwijde keten van financiële producten.

De huidige wooncrisis moet begrepen worden tegen deze achtergrond van (a) vastgoed dat een speelbal wordt in de financiële globalisering, (b) de nieuwe politieke betekenis die vastgoed heeft gekregen door de macro-economische stimuli die het kan creëren, en (c) burgers die gefinancialiseerde subjecten zijn geworden. In het kielzog hiervan zien we de opkomst van beleggers op woningmarkten in verschillende (westerse) landen. Het centrale idee van de woning als investeringsobject heeft aan belang gewonnen en de politiek is er veel aan gelegen niet alleen hoge woningprijzen in stand te houden, maar ook verdere prijsstijgingen mogelijk te maken. Binnen deze context wordt het in algemene zin aantrekkelijker als belegger te opereren.

Dit komt in zijn meest extreme vorm tot uiting in de opmars van een transnationale klasse van 'superrijken' die op de duurste locaties woningen kopen om vermogens vast te leggen. Het gaat dan vooral om investeringen - vaak voor leegstand (buy-to-leave), soms voor verhuur (buy-to-let) - in wereldsteden als Londen en New York (Fernandez, Hofman \& Aalbers, 2016).

In bredere zin hangt de opkomst van kleine particuliere beleggers samen met groeiende scheidslijnen tussen generaties (Forrest \& Hirayama, 2015; Arundel, 2017). Veel landen kennen een oudere generatie van woningkopers die overwegend geprofiteerd heeft van lage instapprijzen en daaropvolgende prijsstijgingen. Zo hebben zij grosso modo aanzienlijk woonvermogen weten op te bouwen (Wind, 2017). In toenemende mate zien zij de woningmarkt als aantrekkelijke plek om hun vermogen te stallen. Het aankopen van een (extra) woning kan dan dienen als oudedagsvoorziening, verzekering tegen tegenslagen of toekomstig zakcent voor de kinderen (Doling \& Ronald, 2010). Jongere generaties worden daarentegen geconfronteerd met een veel minder toegankelijke en betaalbare woningmarkt, zeker als zij niet op ouderlijke steun kunnen rekenen (McKee, 2012; Lennartz, Arundel \& Ronald, 2016). Daarbij komt een arbeidsmarkt die meer en meer gekenmerkt wordt door tijdelijkheid en onzekerheid (Vrieselaar \& Lennartz, 2018). 


\section{Buy-to-let in Nederland}

Buy-to-let-investeerders zijn actief in de particuliere huursector. Tussen 2012 en 2017 is de particuliere huursector in vrijwel heel Nederland gegroeid, met in totaal ruim 170.000 woningen (CBS, 2017). Daarmee groeide het aandeel particuliere huur met 23,4 procent tot 12,4 procent van de totale Nederlandse woningvoorraad. Vooral in de vier grote steden was de toename, in absolute zin, sterk met in totaal 44.000 woningen. Deze ontwikkeling vormt een belangrijke trendbreuk: tot aan het uitbreken van de financiële crisis in 2008 kende de particuliere huursector decennia van aanhoudende krimp. De revival van particuliere huur hangt samen met een herstructurering van de particuliere sector: waar voorheen de meeste particuliere huurwoningen tegen een lage huur aangeboden werden, concentreert de groei zich momenteel in de duurdere vrije sector.

De groei van de particuliere huursector kan op verschillende manieren tot stand zijn gekomen: door buy-to-let-investeringen, door nieuwbouw en door het opkopen en doorverhuren van portfolio's van corporatiewoningen. Het is van belang een duidelijk onderscheid te maken tussen deze verschillende typen investeerders, met verschillende belangen en strategieën. Ook de uiteindelijke gevolgen voor de woningmarkt kunnen verschillen. Niet alle investeringen in huurwoningen kunnen dus onder de noemer buy-to-let geschaard worden. In het vervolg van deze paragraaf kijken we eerst naar de mogelijke invloed van andere investeerders op de particuliere huurmarkt en gaan vervolgens in op de rol van buy-to-let.

\section{Institutionele investeerders}

Als beheerders van kapitaal van bijvoorbeeld pensioenfondsen hebben institutionele beleggers een relatief groot investeringsvolume. Ze vormen daarmee potentieel belangrijke spelers op de woningmarkt. Vanaf 2014 is sprake van een substantiële toename in investeringen in zowel bestaande huurwoningen als nieuwbouw huur door institutionele investeerders (CBS, 2018; NVM, 2018). Desalniettemin lijkt de groei van particuliere huur niet geheel toe te schrijven aan investeringen door institutionele beleggers.

Ook de verkoop van corporatiebezit aan beleggers speelt een rol. $\mathrm{Na} 2010$ zijn dergelijke verkopen flink toegenomen (zie figuur 1). De dreiging van een faillissement van woningcorporatie Vestia is hiervoor een belangrijke verklaring. Als gevolg van deze affaire moest Vestia zelf bezit verkopen, maar ook andere corporaties moesten door middel van verkoop financieel bijdragen aan een solidariteitsheffing (Aalbers, Van Loon \& Fernandez, 2017). Interessant genoeg is er vanaf 2014 juist een scherpe daling waar te nemen in de verkoop van corporatiewoningen aan particuliere huishoudens.

\section{Kleine particuliere beleggers}

Recente discussies in de media en het publieke debat richten zich vaak op het opkopen van bestaande woningen voor verhuur door particuliere investeerders. Deze groep bestaat uit zowel kleine, private investeerders als professionele verhuurders die bedrijfsmatig te werk gaan. Onder de private investeerders vallen 


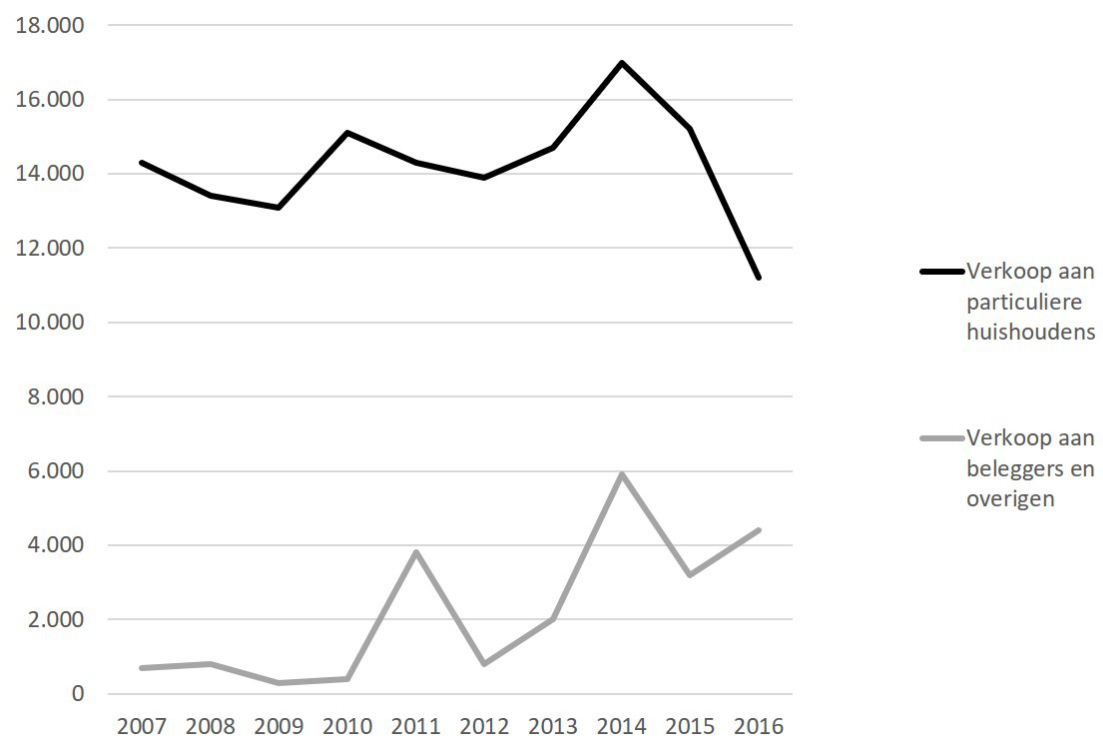

Figuur 1 Verkoop corporatiebezit in Nederland aan beleggers en overigen, en aan particuliere huishoudens (bron: Aedes.nl; eigen bewerking)

bijvoorbeeld investeerders die een woning kopen als oudedagsvoorziening, die een woning kopen voor verhuur aan kinderen of vrienden, die een pand geërfd hebben of die een woning verhuren in afwachting van verkoop. Winstmotieven zijn niet altijd doorslaggevend. Bij professionele investeerders met grotere vastgoedportefeuilles die bedrijfsmatig panden opkopen en verhuren (en soms weer doorverkopen) speelt een winstmotief een prominentere rol. Veel van deze activiteiten kunnen onder de noemer buy-to-let geschaard worden.

Figuur 2 geeft de ontwikkeling weer van aankopen door natuurlijke personen voor verhuur als aandeel van het totale aantal transacties in de periode 2006 tot en met het derde kwartaal van 2016. In deze data zijn ook verkopen van reeds verhuurde woningen meegenomen, dat wil zeggen transacties tussen verhuurders. Daarmee kunnen deze cijfers niet gebruikt worden als direct bewijs voor het omzetten van koopwoningen naar huurwoningen. Ze geven echter wel een duidelijke aanwijzing van het aandeel van de aankopen, per stad, om te verhuren.

In Nederland als geheel is het aandeel aankopen voor verhuur door particulieren met 79 procent toegenomen tussen 2006 en 2016, van 3,3 naar 5,8 procent. In Amsterdam, Rotterdam en Den Haag worden relatief meer woningen door kleine investeerders aangekocht. In 2016 namen zij bijna 13 procent van de woningaankopen in Amsterdam voor hun rekening. Den Haag en Rotterdam volgen met respectievelijk zo'n 11 en 10 procent. Het is opmerkelijk dat Utrecht, waar het aandeel rond het landelijk gemiddelde schommelt, achterblijft.

In enkele middelgrote studentensteden ligt het aandeel buy-to-let structureel hoger dan in de vier grote steden (zie Aalbers e.a., 2018). Zo lag het aandeel aankopen voor verhuur in Maastricht in 2006 al rond de 20 procent. Buy-to-let is dus 


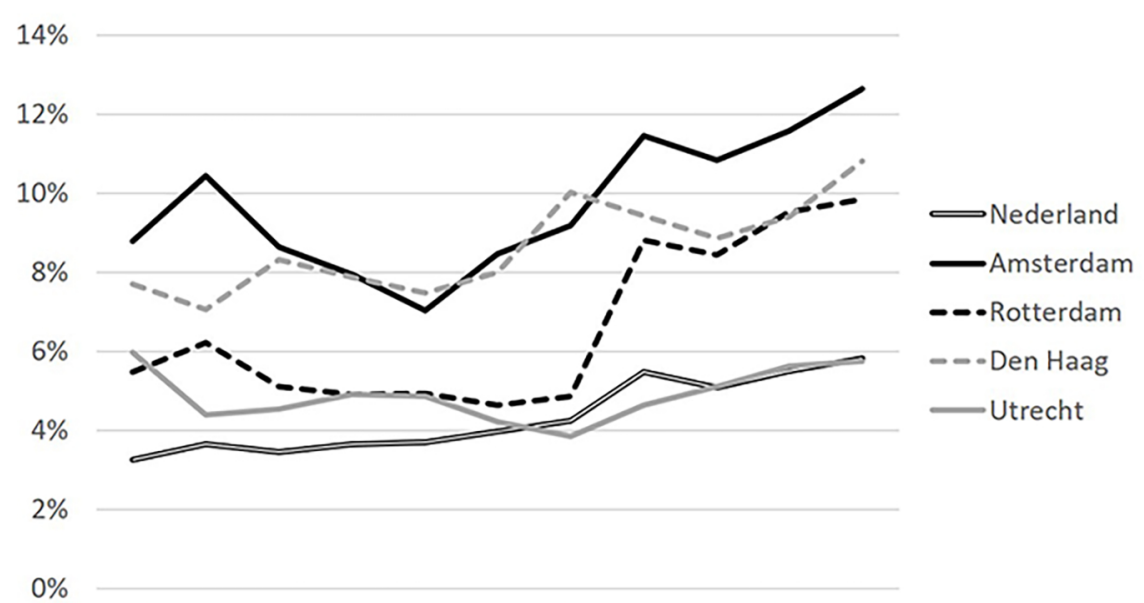

20062007200820092010201120122013201420152016

Figuur 2 Aankoop voor verhuur door particulieren met drie tot vijftig woningen als aandeel van het totaal aantal transacties in de vier grote steden, en Nederland gemiddeld (bron: Kadaster; eigen bewerking). Noot: data voor 2016 tot en met het derde kwartaal

zeker geen nieuw fenomeen. Een verklaring is dat in deze steden de vraag naar particuliere huurwoningen onder studenten relatief groot is.

De groei is daarnaast bovengemiddeld in de grote steden, Utrecht uitgezonderd. In Amsterdam en Rotterdam is sprake van een verdubbeling van het aandeel buyto-let sinds de bodem in 2010 was bereikt (respectievelijk van 7 naar 13 procent en van 5 naar 10 procent). Het aandeel woningen dat in 2016 wordt aangekocht voor verhuur door particuliere investeerders ligt bovendien ook hoger dan in de jaren voor de crisis.

Wat betreft het type woningen dat wordt aangekocht, valt op dat vooral woningen kleiner dan $50 \mathrm{~m}^{2}$ populaire verhuurobjecten zijn. Bijna 30 procent van de aankopen binnen deze categorie is bedoeld voor verhuur. Tussen 2006 en 2016 is een verdubbeling zichtbaar van het aandeel woningen van $50-100 \mathrm{~m}^{2}$ dat wordt gekocht voor verhuur. Deze cijfers suggereren dat vooral huishoudens die op zoek zijn naar kleine woningen, zoals starters, alleenstaanden en senioren, mogelijk te maken krijgen met concurrentie van verhuurders op de koopmarkt.

\section{De rol van het Nederlandse woonbeleid}

De opmars van buy-to-let komt niet zomaar uit de lucht vallen. Zowel langlopende beleidslijnen als recente veranderingen in het woonbeleid spelen een cruciale rol. Beleidswijzigingen met betrekking tot huur en koop stimuleren beleg- 
gers op de woningmarkt niet direct, maar hebben wel ruimte geboden aan hun opmars. Recent beleid moedigt bovendien expliciet de groei van geliberaliseerde huur aan.

\section{Veranderingen in de huursector}

Gedurende de twintigste eeuw was volkshuisvesting een centraal onderdeel van de verzorgingsstaat. Sociale woningbouw domineerde de wederopbouwperiode na de Tweede Wereldoorlog (Van der Schaar, 1987). Tussen 1945 en 1985 nam het aandeel corporatiewoningen toe van nog geen 15 procent tot bijna 40 procent van de Nederlandse woningvoorraad (Musterd, 2014). Vanaf het einde van de jaren tachtig kwam de nadruk echter te liggen op uitbreiding van eigenwoningbezit, ten koste van sociale en vooral particuliere huur. Vooral in de grote steden neemt de huurvoorraad duidelijk af in omvang.

Bovendien wordt de (financiële) speelruimte van woningcorporaties beperkt. Dit is ten dele het gevolg van misstanden, zoals de eerdergenoemde Vestiaaffaire. Ook andere beleidsmaatregelen, zoals de Verhuurderheffing uit 2013, verhogen de lasten voor woningcorporaties (Boelhouwer e.a., 2014). Gevolg is dat er minder financiële speelruimte is, bijvoorbeeld voor nieuwbouw en vernieuwing. De extra lasten zetten bovendien aan tot huurverhogingen en tot woningverkoop - zowel aan eigenaar-bewoners als beleggers.

Ten slotte is toegang tot de sociale-huursector aan banden gelegd. In 2011 heeft de Nederlandse overheid, onder impuls van een klacht van de institutionele woningverhuurders aan het adres van de Europese Unie, een maximale inkomensgrens van $€ 36.798$ bruto per jaar ingesteld. Sindsdien moeten corporaties 90 procent van hun bezit verhuren aan huishoudens met een inkomen tot deze grens. Een gevolg is dat corporatiehuurders steeds vaker tot de allerlaagste inkomens behoren (SCP, 2017). Sociale huur functioneert zo steeds meer als laatste redmiddel. Verdien je iets meer, dan kun je nauwelijks meer terecht in het sociale segment en ben je aangewezen op de vrije markt (Hochstenbach, 2018).

\section{Veranderingen in de koopsector}

Uitbreiding van de koopsector sinds eind jaren tachtig is mede mogelijk gemaakt door soepele hypotheekverstrekking en hoge maximale leenbedragen (steeds hogere loan-to-value- en loan-to-income-ratio's). Instandhouding van de hypotheekrenteaftrek betekent bovendien de facto dat koopwoningen gesubsidieerd worden, en daarmee financieel aantrekkelijker. Het stimuleren van koop en het beleid van hypotheekverstrekkers stelden aanvankelijk meer mensen in staat een woning te kopen (Wind, 2017). Het heeft echter ook geleid tot langdurige prijsstijgingen. Woningbezitters konden hierdoor woonvermogen opbouwen, maar voor outsiders - aspirant-kopers - werd kopen steeds lastiger.

Het stimuleren van de koopsector geschiedt onder andere door fiscaal-financiële ondersteuning. Denk aan de hypotheekrenteaftrek, een aanzienlijke fiscale subsidie. Decennia van royale hypotheekverstrekking en hypotheekrenteaftrek hebben Nederland tot koploper hypotheekschuld gemaakt. Deze schuld heeft stijgende koopprijzen niet alleen mogelijk, maar in veel opzichten ook noodzakelijk gemaakt. Er is immers veel (electoraal) belang bij het in stand houden van hoge 
prijzen. Dit economische model waarbij woningen in toenemende mate als spaarpot dienen, met schuld als brandstof, is de politieke en economische context waarbinnen particuliere investeerders opereren en woningen als een rendabele en vaak ook veilige belegging zien. Woningkopers lopen echter steeds meer tegen de grenzen van betaalbaarheid op na langdurige prijsopdrijving. Alleen de historisch extreem lage rente van de laatste jaren heeft de betaalbaarheid vooralsnog op peil kunnen houden. Bovenop deze constructie van prijsopdrijving door schuld komt nu prijsopdrijving door eigen vermogen.

De toegankelijkheid van de koopsector nam al enkele jaren voor de financiële crisis van 2008 af, maar kwam vooral daarna onder druk te staan. Woningprijzen en verkoopaantallen kwamen in een vrije val, en veel woningen kwamen 'onder water' te staan. In reactie op de financiële crisis zijn de criteria voor hypotheekverstrekking aangescherpt - maximale leenbedragen zijn teruggebracht en er worden strengere voorwaarden gesteld. Het speelveld op de koopmarkt is hierdoor veranderd, waarbij de positie van de kapitaalkrachtigen verder versterkt is. Het gaat dan bijvoorbeeld om vermogende huishoudens - doorgaans oudere insiders op de woningmarkt - en investeerders. Zij kunnen hun vermogen aanwenden om andere woningzoekenden zoals koopstarters te overbieden. Inmiddels stijgen de woningprijzen in veel steden en regio's weer in hoog tempo, waardoor toegang tot de koopsector nog meer bepaald wordt door inkomenspositie en vermogen.

\section{Woonbeleid en particuliere huur}

Recent beleid in de huursector draagt kortom bij aan een krimpende sociale huurvoorraad, voorbehouden aan lage inkomensgroepen. Tegelijkertijd staat ook de toegankelijkheid van de koopsector onder druk. Veel huishoudens komen hierdoor in een spagaat: ze verdienen te veel om in aanmerking te komen voor een sociale huurwoning en te weinig om een hypotheek te krijgen om een woning te kopen die bij hun levensfase en huishouden past. Nieuwkomers uit andere delen van het land of het buitenland komen de sociale huursector al helemaal niet in. Deze groepen vallen tussen wal en schip. Zij zijn als gevolg afhankelijk van particuliere huur, waardoor het ceteris paribus aantrekkelijker is om te investeren in particuliere huur. Dergelijke beleidswijzigingen bieden kortom een verklaring voor de huidige groei van de particuliere huurmarkt.

Het regeringsbeleid is bovendien actiever geworden in het direct stimuleren van particuliere huur. Uitbreiding van de vrije-huurmarkt - en dan in het bijzonder het zogenaamde middensegment met huren tot $€ 1000$ - wordt inmiddels gepresenteerd als dé oplossing om groepen die tussen wal en schip vallen te huisvesten (Hochstenbach, 2018). Het regeerakkoord van het kabinet-Rutte III stelt bijvoorbeeld dat er meer huurwoningen in de vrije sector moeten komen. De Nationale Woonagenda, gepresenteerd in mei 2018, legt verder de nadruk op uitbreiding van het middensegment - onder meer door verkoop van corporatiewoningen aan beleggers. Het idee is dat buy-to-let zo een bijdrage levert aan uitbreiding van de krappe vrije-huurmarkt.

Bovendien zijn er al enkele specifieke maatregelen genomen die investeren in huurwoningen aantrekkelijker maken. Sinds 1 oktober 2015 wordt bijvoorbeeld 
de WOZ-waarde (waardering onroerende zaken) van een woning gebruikt voor het bepalen van de maximale huurprijs in het woningwaarderingsstelsel. Gevolg is dat op populaire plekken een huurwoning makkelijk van het gereguleerde segment naar de vrije sector overgeheveld kan worden. Dit stelt verhuurders in staat hogere huren te vragen en maakt buy-to-let aantrekkelijker. Per 1 juli 2016 kunnen particuliere verhuurders tijdelijke huurcontracten van maximaal twee jaar aanbieden, waar voorheen contracten van onbepaalde duur standaard waren. Dit betekent een afzwakking van de huurbescherming, ten gunste van verhuurders.

\section{Conclusie}

Buy-to-let is de afgelopen jaren bezig met een sterke opmars. Het aandeel woningen dat wordt aangekocht door kleine investeerders voor verhuur is tussen 2006 en 2016 met 79 procent gestegen. Die toename staat niet op zichzelf, maar is het gevolg van zowel nationale beleidskeuzes als van maatschappelijke, economische en politieke ontwikkelingen die Nederland deels ontstijgen. Waar woningen voorheen primair als onderdak en thuis werden gezien, is de laatste decennia een verschuiving zichtbaar naar woningen als investering. Overheden verwachten in toenemende mate dat huishoudens hun eigen welvaartsvoorziening regelen door in een woning te investeren.

Beleidskeuzes hebben op verschillende manieren een bijdrage geleverd aan de toename van buy-to-let. Bijvoorbeeld door het aanscherpen van toegang tot de sociale huur en door koopprijzen met hypotheekschuld op te drijven, maar ook door de private huurmarkt te liberaliseren. Toenemende woningaankopen door verhuurders drijven de prijzen van koopwoningen op. Investeerders zijn daarbij niet gebonden aan dezelfde hypotheekeisen en hebben meer kapitaal beschikbaar en trekken vaker aan het langste eind.

De groei van buy-to-let is geen uniek Nederlands fenomeen, de problemen die er mee geassocieerd worden evenmin. In het Verenigd Koninkrijk, Canada, NieuwZeeland en Australië wordt in dit kader al beleid gevoerd tegen buy-to-let. Het gaat dan zowel om maatregelen die de effecten van buy-to-let tegengaan, als om maatregelen die het fenomeen als geheel proberen te beperken. Het betreft fiscale maatregelen, zoals het verhogen van overdrachtsbelasting in het Verenigd Koninkrijk (Jones, 2017) en niet-fiscale maatregelen zoals in Nieuw-Zeeland, waar aankopen van woningen door buitenlandse beleggers sinds 2017 verboden zijn (Brocket, 2017).

Ook binnen de Nederlandse politiek, en dan vooral vanuit de grote steden, groeit de roep om maatregelen die buy-to-let als geheel beperken of de uitwassen tegengaan. Vooralsnog zijn dergelijke maatregelen niet van kracht en groeit het aandeel buy-to-let. Dit heeft mogelijk als gevolg dat lagere inkomensgroepen moeilijker of helemaal geen woning kunnen vinden en uiteindelijk uit de stad verdrongen worden. Daarnaast neemt de vermogensongelijkheid tussen insiders en outsiders op de woningmarkt verder toe: zij die een woning hebben profiteren van de toenemende waarde, terwijl huurders alleen maar hogere huurlasten hebben. Dit 
betekent een verdieping van de stedelijke wooncrisis en het aanscherpen van ongelijkheden.

\section{Literatuur}

Aalbers, M.B. (2008). The financialization of home and the mortgage market crisis. Competition \& Change, 12 (2): 148-166.

Aalbers, M.B., Bosma, J.R., Fernandez, R., \& Hochstenbach, C. (2018). Buy-to-let gewikt en gewogen. Leuven/Amsterdam: KU Leuven/Universiteit van Amsterdam.

Aalbers, M.B., Loon, J. van, \& Fernandez, R. (2017). The financialization of a social housing provider. International Journal of Urban and Regional Research, 41 (4): 572-587.

Aedes.nl. Ontwikkeling woningvoorraad corporaties 2007-2016.www.aedes.nl/feiten-encijfers/woning/hoe-ontwikkelt-het-bezit-van-corporaties-zich/expert-hoe-ontwikklthet-bezit-van-corporaties-zich.html, geraadpleegd op 20 mei 2018.

Arundel, R. (2017). The end of mass homeownership? Housing career diversification and inequality in Europe (proefschrift Universiteit van Amsterdam).

Boelhouwer, P.J., Elsinga, M.G., Gruis, V.H., Priemus, H., Schaar, J. van der, \& Thomsen, A.F. (2014). Wonen 6.0: over de toekomst van de sociale huisvesting in Nederland. Delft: TU Delft.

Brockett, M. (2017). New Zealand Bans Foreign Home Buyers After Price Surge. Bloomberg. www.bloomberg.com/news/articles/2017-10-31/new-zealand-to-slap-homebuying-ban-on- foreigners-to-ease-market, geraadpleegd op 20 mei 2018.

CBS (2017). Eigendom woningvoorraad. Den Haag: Centraal Bureau voor de Statistiek.

CBS (2018). Beleggingen in miljarden euros in woningen in Nederland door institutionele beleggers. Den Haag: Centraal Bureau voor de Statistiek.

Couzy, M., \& Dun, M. van (2017, 4 november). Groeiende ongelijkheid op de woningmarkt: van wie is deze stad eigenlijk? Het Parool.

Doling, J., \& Elsinga, M. (2012). Demographic Change and Housing Wealth: Home-owners, Pensions and Asset-based Welfare in Europe. Dordrecht: Springer Science \& Business Media.

Doling, J., \& Ronald, R. (2010). Home ownership and asset-based welfare. Journal of Housing and the Built Environment, 25 (2): 165-173.

Fernandez, R., \& Aalbers, M.B. (2016). Financialization and housing: Between globalization and Varieties of Capitalism. Competition \& Change, 20 (2): 71-88.

Fernandez, R., Hofman, A., \& Aalbers, M.B. (2016). London and New York as a safe deposit box for the transnational wealth elite. Environment and Planning A, 48 (12): 2443-2461.

Forrest, R., \& Hirayama, Y. (2015). The financialisation of the social project: Embedded liberalism, neoliberalism and home ownership. Urban Studies, 52 (2): 233-244.

Hochstenbach, C. (2017). Inequality in the gentrifying European city (proefschrift Universiteit van Amsterdam).

Hochstenbach, C. (2018). Meer woningen in het middensegment zijn niet de heilige graal. Sociale Vraagstukken.

Hudson, M. (2012). The Bubble and Beyond: fictitious capital, debt deflation and the global crisis. Dresden: ISLET.

Jones, R. (2017). Buy-to-let UK property sales fall by almost $50 \%$ in a year. The Guardian. www.theguardian.com/money/2017/jun/22/buy-to-let-uk-property-sales-fall-byalmost-50-in-a-year, geraadpleegd op 20 mei 2018. 
Langley, P. (2006). The making of investor subjects in Anglo-American pensions. Environment and Planning D: Society and Space, 24 (6): 919-934.

Lennartz, C., Arundel, R., \& Ronald, R. (2016). Younger adults and homeownership in Europe through the global financial crisis. Population, Space and Place, 22 (8): 823-835.

McKee, K. (2012). Young people, homeownership and future welfare. Housing Studies, 27 (6): 853-862.

Musterd, S. (2014). Public housing for whom? Experiences in an era of mature neo-liberalism: The Netherlands and Amsterdam. Housing Studies, 29 (4): 467-484.

NVM (2018). Prijzen in vrije huursector blijven stijgen, ondanks meer nieuwbouw. Nieuwegein: Nederlandse Vereniging van Makelaars en Taxateurs.

Schaar, J. van der (1987). Groei en bloei van het Nederlandse volkshuisvestingsbeleid: volkshuisvesting in theorie en praktijk. Delft: Delft University Press.

Schwartz, H., \& Seabrooke, L. (2008). Varieties of residential capitalism in the international political economy: Old welfare states and the new politics of housing. Comparative European Politics, 6 (3): 237-261.

SCP (2017). De sociale staat van Nederland. Den Haag: Sociaal en Cultureel Planbureau.

Vrieselaar, N., \& Lennartz, C. (2018). Waarom jongeren steeds minder en ouderen steeds vaker een huis kopen. Utrecht: RaboResearch Economisch Onderzoek.

Wind, B. (2017). Housing Wealth in Europe: Institutions and Inequality (proefschrift Universiteit van Tilburg). 